\title{
An Exploratory Study of the Role of Human Resources Management in the Process of Change
}

\author{
Ali El-Dirani, Mohammad Mahdi Houssein, Hussin J. Hejase* \\ Faculty of Business Administration, Al Maaref University, Beirut, Lebanon \\ Email: ^hhejase@mu.edu.lb
}

How to cite this paper: El-Dirani, A., Houssein, M.M. and Hejase, H.J. (2020) An Exploratory Study of the Role of Human Resources Management in the Process of Change. Open Journal of Business and Management, 8, 156-174.

https://doi.org/10.4236/ojbm.2020.81010

Received: October 22, 2019

Accepted: December 14, 2019

Published: December 17, 2019

Copyright $\odot 2020$ by author(s) and Scientific Research Publishing Inc. This work is licensed under the Creative Commons Attribution International License (CC BY 4.0).

http://creativecommons.org/licenses/by/4.0/

\begin{abstract}
The process of change in organizations is usually triggered by business-related environmental factors which if not managed adequately result in uncertainty and volatility leading to a situation where an organizations may lose competitive advantage especially if its response is reactive. Consequently, organizations' preparedness and pro-activeness across all functional departments are key success factors in terms of the wise use of resources/capabilities. Of particular significance is the human resource (HR) function whose role is fundamental in the change process necessary to accommodate change. This research aims to assess the role of HR in the ongoing process of change in organizations by identifying the change process, the functions and roles of $\mathrm{HR}$ in this process and how these interrelate. Exploratory qualitative research is used based on primary data obtained from semi-structured interviews. A willing small sample of HR experts and practicing professionals is selected. The research outcomes shed light on the HR practitioners role in the process of change, and an assessment of the nature of the intertwining effect to develop appropriate response policies in a more effective and efficient manner. Findings, though pertinent to a small group and may not be generalizable, act as an eye opener to organizational policy makers as well as HR managers.
\end{abstract}

\section{Keywords}

Change, Role of Human Resource Management, Leadership, Lebanon

\section{Introduction}

Schein [1] contends that "the fundamental assumptions underlying any change in a human system are derived originally from Kurt Lewin in 1947" (p. 299) 
whose process has three steps:

"Unfreezing the organization from its current state; implementing the desired change; and refreezing the organization in a new desired sate" [2]. The benefits of the aforementioned steps are to drive the change in a systematic way, plan for the change, and mitigate the impact of change on the organization. Though, one well known problem to the change process is employees' resistance which negatively affects the whole process of change and if not dealt with adequately leads to undesired results. Consequently, and according to Jones [2], organizations try to mitigate the negative impact of change using several organizational development (OD) techniques including "education and communication, participation and empowerment, facilitation and support, bargaining and negotiation, and coercion", also other OD techniques are used in order to promote change like counseling, training, and team building, ... Furthermore, Cummings and Worley [3] assert that organizational development intervention is manifested in specific actions namely, "1) Human Process Issues including communication, problem solving, decision making, interacting and leading; and 2) Human Process Interventions including interpersonal, group process, and organization process approaches" (p. 155).

Leading the change process toward mitigating threats relies on the human capital, as stressed by Hussain, Lei, Akram, Haider, Hussain and Ali [4] who posit that "the dominant role of leadership and employee involvement in change process are necessary for bringing effective change in management" (p. 126). Further, Oreg [5] and Furst \& Cable [6] assert that employees' active roles in organizational change tend them toward acceptance of the change process and positive feelings, respectively.

This study aims to shed light and assess the role of the HR in the change process from a small willing sample of Lebanese HR experts' and professionals' points of view. Thus, the objectives of this study are as follows:

- Identify the process of change.

- Shed light on the role of HR (Functional area, managers, and employees) in the ongoing process of change in organizations.

- Assess the intertwining relation between the change process and the HR role in this process.

This paper is organized as follows: In section 2, a review of the literature is presented. Section 3 describes the research methodology including approach, sampling and interview design. The following Section 4 presents the results and discussion, and then Section 5 presents a closure to the paper with conclusions, recommendations and implications.

\section{Literature Review}

Gartner [7] provides important facts about change in organizations, whereby " $73 \%$ of the organizations expect more change initiatives in the next few years, and only a small minority expects the pace of change to decelerate. Unfortunately, many organizations fail to implement change effectively. In fact, only a 
third of change efforts are clear successes, $16 \%$ show mixed results, and half are clear failures" (Para 1). Therefore, organizational change embodies strategic moves. Cummings and Worley [3] argue that "business strategies and organizational systems must be changed together in response to external and internal disruptions. A strategic change plan helps members manage the transition between a current strategy and organization design and the desired future strategic orientation" (p. 160). Jones [2] defines it as "the process by which organizations move from their present state to some desired future state to increase their effectiveness". Therefore, planned organizational change needs adequate management of the change process accompanied by employees' awareness of the change to stimulate the process [8]. Further, Cook \& Macaulay [9] (p. 1), define change management as the daily bread of organizations, where technological advancement, extensive rate of competition, globalization, and many other factors govern the way organizations operate and change. Moreover, Lockwood [10] notes that the Society for Human Resource Management defines change management as "a formal process for organizational change that includes a systematic approach and application of knowledge" (p. 31). Furthermore, Lockwood adds that change management "means defining and adopting corporate strategies, structures, procedures, and technologies to deal with change stemming from internal and external conditions" [10].

A change process necessitates that leaders not only engage organizational staff in critical decision making, but also in the implementation of change. Collarbone [11] contends that "Leaders need to build authority within individuals, This frees everyone to work at full potential, creating increased efficiency, motivation and effectiveness and increase leadership capacity and capability at all levels" (p. 3). The aforementioned is congruent with Mathieu, Gilson and Rubby [12] who stress that empowering employees with authority and responsibility leads to their effective involvement.

According to the Society for Human Resource Management, SHRM [13], "Business managers who want to undertake major transformation to stay competitive must work with HR staff to gain employee acceptance and support" (Para 13). HR practitioners are aware of the aforementioned requirements for the success of change, actually HR staff are a major part of it and they play an active role in the change process and its outcomes. "HR can play a dual role in change management by initiating and leading the change and by serving as a facilitator for changes that other leaders and departments initiated" [13] (Para 18).

\subsection{Change as a Process}

Three models are reviewed in this paper. Kurt Lewin [14] researched group decision-making, implementation and social change leading to his planned organizational change approach. Lewin's model consists of three steps based on intentional change in the organization and posits that change initiators may opt to use different strategies to implement the change intended. The three steps are as follows: 1) unfreezing the status quo considered the equilibrium state, where- 
by it is necessary to overcome the challenges of individual resistance and group conformity; 2) the movement, that is, to move the target system to a new level of equilibrium; 3) refreezing, occurring after the implementation of change to achieve sustainability [15].

The second model for change is Kotter's model introduced in 1995. This model is considered more as a sequence of actions, or a checklist, that organizations can adopt for implementing the process of change, but according to Burnes [16], the aforementioned steps represented a process not a checklist. The eight steps model as Kotter [17] suggested are: "Creating sense of urgency; forming a powerful coalition; create a vision for change; communicating the vision; getting rid of obstacles; creating short-term wins; building on change; and institutionalizing new approaches" (p. 61).

Anderson and Anderson [18] are credited for the third model of planned change which views change based on three perspectives namely content, people and process and is divided into nine cyclical phases. Further, the model provides a thorough coverage of the whole change process and explains it as a cyclical process. It consists of four critical factors: "charismatic leadership, organizational crisis, understanding across the organization of the urgency of the situation, and a trusting relationship between the leader and the organization members" (p. 151).

\subsection{Triggers of Change}

Researchers tend to discuss the external factors of change more widely, where they affect organizations the most, and according to McMillan [19], most organizations are faced with external forces like globalization and modern technology which add uncertainties to be dealt with. Oakland \& Tanner [20] suggested two types of factors of change, the external change drives (competition, customer requirements; demand from other stakeholders; government; and regulatory demands) and the internal change drives of the organization (improvement targets applied to quality of goods, products and services; to operational efficiency; and to the process). The aforementioned is affirmed by Ryerson University [21], "change stemming from internal and external conditions" (p. 4).

\subsection{Levels of Change}

Cameron \& Green [22] contend that change occurs in organizations on three main levels namely, individual, team and organizational levels.

\section{Individual level:}

Ryerson University [21] posits that employees are the main entity affected by the change. "It is critical that they are involved in the process and understand how the change initiative will impact their current state" (p. 8). Therefore, individuals in any organization constitute a critical level whereby the idea of change needs to be addressed. Cameron \& Green [22] describe four theories in their book to explain this level namely, "Behavioral approach; Cognitive approach; 
Psychodynamic approach, and Humanistic Psychological approach" (pp. 12-13).

\section{Team level:}

Organizations consist of different types of working groups who are involved in the change.

According to Collarbone [23] "Change teams have a profound effect on organizational culture. For example, staff feel more included and involved in the running of the organization and feel more of a sense of ownership (both of the change process itself and of the changes that are made). People support what they help to create" (p. 76). Further, Todnem, Kuipers and Procter [24] assert that "teams are important objects of change, are meaningful units to contribute to various types of change" (p. 7).

\section{Organizational level:}

According to Mar [25], "Organizational Change Management is the practice of managing enterprise changes such as mergers \& acquisitions, restructuring, process changes and culture transitions. It's often focused on the people side of change-socializing change to reduce resistance and gain acceptance. In many cases, organizational change management is an executive management function or is a program run by the human resources department" (Para 5-6).

\subsection{Resistance to Change}

Paycor Incorporation [26], believes that "People prefer stability and comfort over change in both their personal and professional lives. Over the past few years, change has become a norm in the business world. Companies that can manage change with ease will have the upper hand over their competition" (Para 3). Further, Yılmaz \& Kılıçoğlu [27] assert that "resistance to change is any attitude or behavior indicating no willingness to support or make a desired change. In fact, resistance to change is a resistance to loss of something that is valuable or loss of the known by moving to the unknown" (p. 16).

Expert Program Management [28] posit that people resist change in four common ways namely, "[1] when they feel that they, personally, will lose something of value, [2] when they misunderstand the implications of the change, [3] when they assess the situation differently from those initiating the change, and [4] when they have been working the same way successfully for years)" (Para 8, $10,12,15)$. Similarly, Paycor [26] identified 5 causes for resistance to change confirming the aforementioned ways namely, Job loss; poor communication and engagement; lack of trust; future is unknown; and poor timing.

Researchers classify resistance to change based on three sources of the organization, "organizational, group, and individual sources" [29] (p. 646), as well as along three entities which may cause damage to the intended change in any organization namely, employee resistance, executive resistance and customer resistance [30] (Para 3-5).

\subsection{Human Resource Roles in Change}

Griffin [31] contends that "the success or failure of an organization depends 
largely on the competence of its people" (p. 7). Also, Benedict [32] asserts that "change management leaders must promote awareness and understanding of the change initiative to influence employees' willingness to embrace the change. HR is the obvious candidate for the role of leading the people side of change" (p. vii). Adeniji, Osibanjo and Abiodun [33] contend that the concept of HR management "includes employees identifying the interests and goals of the organization, and be aligned and committed in achieving these goals. It involves employees adapting willingly to change within the organizational structure without any strife or prejudice" (p. 144). Confirmed by Macky and Boxall [34] who stressed that HRM practices influence employee attitudes and behavior. Further, Tummers, Kruyen, Vijverberg and Voesenek [35] assert that the HR function has to act on the proactivity of the employees. Also, "proactive behavior is change oriented. Consequently, proactive employees intend to alter the self, co-workers, or the work context to adapt to the anticipated changing conditions. Hence, higher levels of proactivity reduce unnecessary workload and facilitate organizational change" (pp. 5-6). On the other hand, Benedict [32] reports that when "HR is involved in processes related to major organizational changes, it performs a variety of functions associated with the communication, implementation and tracking of such changes" (p. 7). Furthermore, Lockwood [10] stresses on the fact that, "HR has the ability to make a significant impact and contribution to the organization by initiating change, leading change and measuring change effectiveness" (pp. 31-32). Five areas were identified by Lockwood [10] as essential for HR to demonstrate value for change management. These are as follows:

"1) Communicating clearly plans and goals regarding change initiatives;

2) Hiring and developing good leaders;

3) Designing and implementing transparent reward systems;

4) Giving people the opportunity to be involved in the processes; and

5) Overall, making each interaction with internal clients a positive experience" (pp. 31-32).

Moreover, Mamin Ullah [36] believes that "HR Professionals should play the required roles to make the change effective by keeping employees high spirited and on the right track during and irrespective of the degree of organizational change. The roles of HR Professionals are not only important to manage the organizational change but also to create a culture of change in an organization" ( $p$. 123). And more recently, Browning [37] stresses the role of HR by the fact that "companies wanting to successfully lead employees through adoption of an organizational change must follow a systematic, proactive approach that incorporates four primary steps: overcoming resistance, engaging employees, implementing change in phases and communicating the change" (Para 6).

\section{Methodology}

Hejase and Hejase [38] contend that "through exploratory research, a researcher acquires deeper knowledge as to how to convert the problem of not having facts about the subject into a structured one" (p. 80). This research aims to elucidate 
the HR role in change management. However, to the best of the researchers' knowledge the aforementioned research is not conducted in Lebanon. For that, primary data is needed to be collected from the field. Therefore, this study is exploratory conducted to study the topic using an inductive approach and a qualitative research methodology.

\subsection{Interview Design}

Primary data collection was performed using semi-structured interviews based on a structured questionnaire. Questions selected were sequentially arranged, simply worded, and using an open end style. The aforementioned helps organize the respondents' thoughts and offers the researchers focused responses from different individuals, a fact that helps performing good content analysis.

The questions' content was designed taking into consideration the research objectives and the literature assessment including the process of change and then focusing on the HRM role in that process. A total of eleven questions addressed the definitions of organizational change, change management, process of change, role of HR, role of $\mathrm{HR}$ in the change process, initiatives to reduce resistance, leadership roles, link between HR and change and finally proposition of a scheme.

\subsection{Sample Size}

Participants were selected conveniently (non-probabilistically) based on their willingness to participate as well as based on their experience and knowledge of the topic. Qualitative narrative analysis approach was used to analyze the content from interviews focusing on using the stories and experiences shared by people to address the research objectives. Data was collected during the period extending from February till April 2019. There are 70,062 registered Lebanese companies [39] (p. 11). The sample size is 398 participants in case quantitative analysis is performed with $95 \%$ significance, representing a population of 75,000 individuals assuming each company in Lebanon has at least one person expert in HR issues beside other professionals and instructors. However, this research represents a probe for the subject needed to identify selected variables so that a more in depth research is carried out later, therefore a qualitative research needs a minimum number of 10 to 15 interviewees to explore the topic under research, especially if experts are chosen.

All participants were human resource professionals and managers in addition to experienced academics in HRM and change management. Initially twelve professionals were approached, and only 6 were committed to an interview whose duration was two hours. However, later on another trial was performed during the month of June, and 20 professionals were approached whereby 6 more agreed to participate (see Table 1). Therefore, the response rate was 37.5\% $(12 / 32)$. Further, all participants were informed that their responses are confidential and will be only used for the analysis of this research. 
Table 1. Participants were classified.

\begin{tabular}{ll}
\hline Interviewee & Status \\
\hline Interviewee $1,2, \& 3$ & $\begin{array}{l}\text { HR managers and officers at an educational institution } \\
\text { (Al Maaref University, Lebanese American University and University for Sciences and Arts in Lebanon) }\end{array}$ \\
Interviewee 4 & HR manager at a Media Organization \\
Interviewee 5, 6, \& 7 & HR academic professors (Al Maaref University, Lebanese American University) \\
Interviewee 8, 9 \& 10 & Consultants and HR experts \\
Interviewee 11 and 12 & HR Training Institution \\
\hline
\end{tabular}

\section{Results and Findings}

Responses were collected from the interviewees and were analyzed following content analysis and based on dimensions discussed earlier in the literature review. All responses are presented in the form of Exhibits as classified.

\section{Change Triggers}

The triggers in this research mean the forces from the external and internal business environment that stimulate change in the organizations. Interviewees' comments are depicted in Table 2.

The General Role of HRM in Change Management

Interviewees tend to believe that HR professionals must be proactive rather than reactive to handle today's world changes and it is not sufficient anymore to act classically to a certain threat. To handle change one must handle core functions in human resources that can affect the change process. See Table 2.

Oakland \& Tanner [20]; McMillan [19]; Ryerson University [21]; and Robbins \& Coulter [40] confirmed the aforementioned inputs reported in their research that organizations are affected by both internal and external forces which may include many different triggers.

In general academics and professionals agree that the general role of HR in the change process is managing change with a methodology that reduces resistance to its lowest levels possible, because human resources must understand people and their concerns and fears, where some consider HR as the facilitator of the change process while others consider it to be supportive.

Interviewees being professionals, experts and academicians, are clearly aware about the role of HR in the quest to reduce resistance and the endeavor to clarify the reasons and process of change to lower the organization's community.

According to Zafar, Iqbal, Azad, \& Afsar [41], "top management envisions the broader picture and motivates the change audience through change agents" ( $p$. 57). However, it is the HR function which spreads around this change vision. "HR communication should be quick, precise and clear that can be understood by a wide range of people" (p. 57). Along the aforementioned, Lunenburg [42] asserts that "the methods used include job enrichment, goal setting, and behavior modification. The major assumption underlying this orientation is that if individuals change their behavior, the organization will also change, providing enough people within the organization change" (p. 2). 
Table 2. Change triggers.

\begin{tabular}{l} 
Change Triggers \\
\hline 1) Competition for talent \\
2) HR Automation \\
3) Upgrading of Performance Appraisal Systems \\
4) New Training \& Development requirements \\
5) Building networks with talent sources \\
6) Social media for recruitment
\end{tabular}

HR Managers \& Officers

HR Media Co.

HR Professors

"Top management plans strategically spanning 3 to 5 years, yet this time line changes in span according to the rapid change in the environment, and when any unique change occurs in the organizational environment, the top management must modify their plans to adapt to that change."

"It all depends on the nature of the organization and the nature of the changes occurring where it is vital for that organization to adapt to changes occurring to insure the organizations sustainability".

1) Need for Updated talent

2) Technology requirements

3) Innovation

4) Social media as a new platform for promotion

"Our clients are demanding for more innovative products"

"Recently we are getting more requests to design promotional campaigns utilizing competences like digital marketing, profiling users of social media, etc. Therefore triggering changes in our HR competencies"

1) Employers' need for new competencies

2) Automation

3) Need for soft skills

4) The need to close gaps between new graduates' skills and market requirements

"Triggers of change vary a lot, and every event that affects the organization can be considered a trigger of change, whether it had a positive or a negative effect and whether it was on an individual level, team level, or organizational level, those events could be either external like an increase in the competition, economical changes, technological changes, socio-cultural changes, political changes, or even changes in the regulation of the country the organization operates in"

"HR must follow up with the change process"

"implemented change becomes part of the organizational culture"

1) Upgrading HR strategies

2) Talent management requirements like succession planning

3) HR innovation

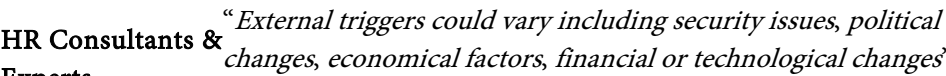
Experts

\section{Role of HRM in Change Management}

1) Strategic planning to respond with agility

2) Institutionalizing quality cultures

3) Adoption of new HRIS systems

4) Reducing resistance to change with employees' engagement

"Today's challenges differ from what was happening in the past, and the HR role and approaches are more strategic"
"In the past as a media organization, we used to focus on television, but a change occurred that made a real challenge to the whole crew, which is the emergence of social media which affected television widely, but with good planning and change management we were able to keep-up with those changes."
1) Employee engagement

2) Training \& Development needs

3) Modifying strategies to cope with new changes

4) Instituting a sense of urgency with all stakeholders

“We teach our HR students that employees engagement is a critical success factor to counter change ... as demanded by new HR roles"

"there are many events that can affect the organization and can be considered internal triggers for change such as a change in systems, processes, management, or introducing new talents to the organization among other things"

1) Redefine Organizational Objectives to cope with change

2) Design new $T \& D$ plans

3) Review Performance Appraisal systems

4) Instituting better incentive systems

"Effectively being transparent with employees when discussing careers as well as performance appraisals are conducted 


\begin{tabular}{|c|c|c|}
\hline \multirow{3}{*}{ HR Training Co. } & 1) New T\&D requirements & 1) $\mathrm{T} \& \mathrm{D}$ as a strong engagement tool involving employees \\
\hline & $\begin{array}{l}\text { 2) New competencies like soft skills } \\
\text { 3) Social media recruitment requirements }\end{array}$ & $\begin{array}{l}\text { "Inviting clients to the design of training workshops to } \\
\text { institute their needs effectively" }\end{array}$ \\
\hline & $\begin{array}{l}\text { "We are continuously modifying our T\&D plans according to } \\
\text { dynamic clients' needs and wants" }\end{array}$ & $\begin{array}{l}\text { "Engaging employees with planned T\&D helps to reduce } \\
\text { resistance to change" }\end{array}$ \\
\hline
\end{tabular}

The Specific Role(s) of HRM in Change Management (the Five Functions)

Participants were asked to address the specific HR role in change management according to the five HR functions namely, Workforce Planning (WFP), Human Resource Development (HRD) (including Training \& Development (TD) + Performance Management (PM)), Total Rewards (TR), Employee \& Labor Relations (ELR), and Risk Management (RM). Their responses were as shown in Table 3.

All interviewees agree that the right recruitment and the right selection is essential for an organization not just in the change process but in all stages of the organizational life.

Human Resource Development (HRD)

This role within HR is extremely important in the change process. HRD has two main functions which are training and development and performance management, and when implementing any change an emergent need for training arises no matter what the change is, whether it was in culture, structure, processes, technology, operations, etc. where employees must be trained for those new changes.

The responses depicted in Table 4 must be put in a clearer context especially that foreign HR experts warn about dealing with change as a set of separate projects including training and development of employees, for example Walcroft [43] reports "Change is often seen as an initiative or series of programs, which may or may not be connected to each other, and each one can often run out of momentum.” Moreover, People Management Insight's [44] report quotes Matt Jenkins, head of consulting at Footdown Co., saying “it's important that organizations are aware that employees go through the change curve at different speeds" (p. 11). The views above, are basic to mitigate resistance though the challenge becomes providing full information and involvement in the process starting with the initial steps.

Total Rewards (TR)

Interviewees (all of them) contend that when evaluating the total rewards application which the HR function addresses, it is built up initially in the organization and rarely modified unless there is an external factor like new governmental laws, or an economic inflation in the country that the organization operated in, those rewards systems must be built up initially to motivate change and change agents.

Korn Ferry [45] contends that "for a rewards strategy to be truly effective, it must be implemented using a change management process that drives understanding, eases adoption and utilization, and keeps a laser focus on delivering intended results" (Para 1). 
Table 3. Specific Roles of HRM in Change management.

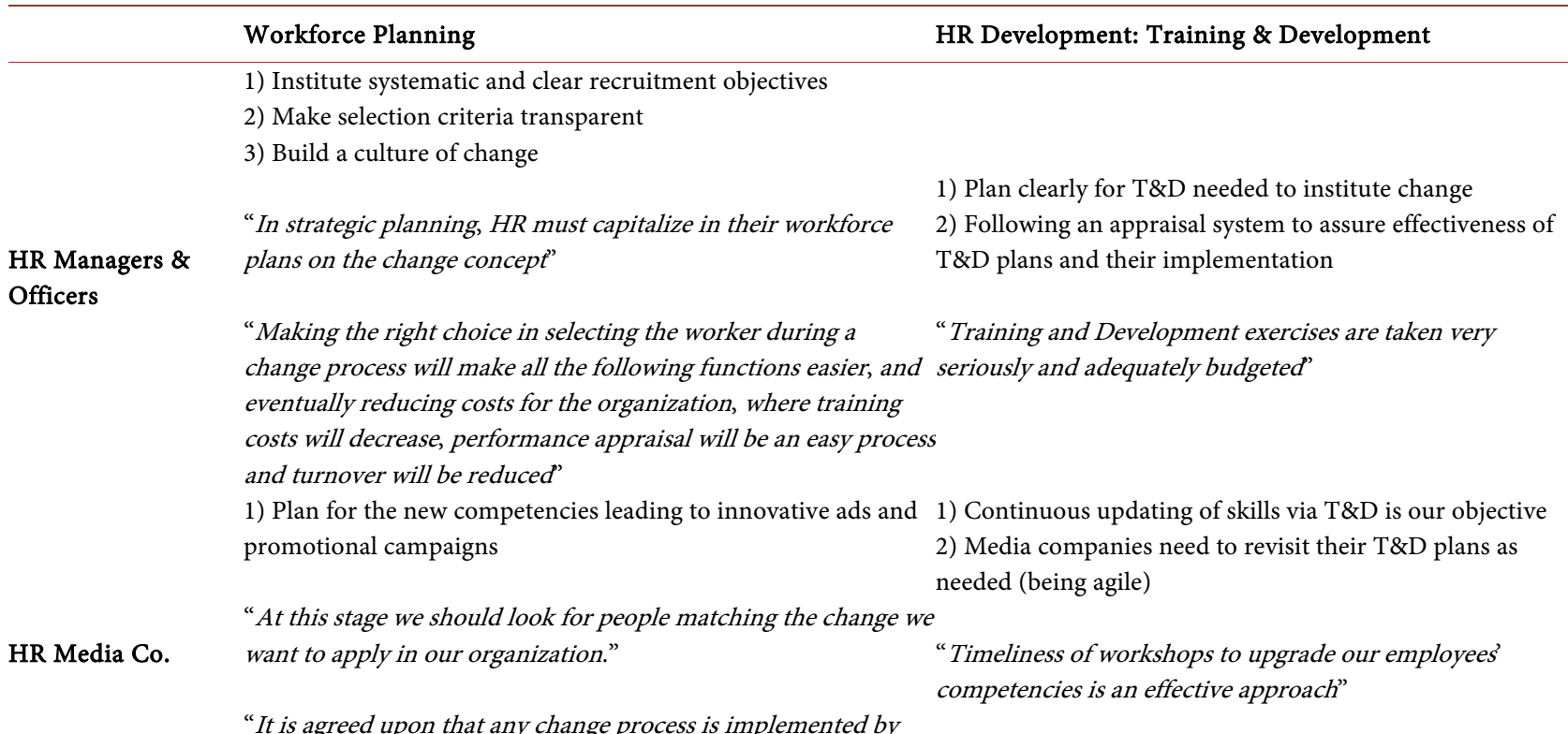
humans, where those humans are the core of the change process "Human behavior issues are considered in the training for therefore selecting the right people leads to make change right." better communication with clients"

1) Change must be supported in the organization's strategy

2) Plan for employees' engagement for example using

"Management by Objectives"

1) An open system approach is justified to include the

"On an operational level, recruitment when needed in triggers' impact on T\&D

implementing a certain change must be adaptable with those changes"

2) Systematic T\&D plans including the new competencies

HR Professors

needed must be shared with employees

"Relying on talented employees during the planning helps in the conducting module training through workshops" implementation process not to mention reducing the costs of that change and reducing resistance levels"

1) Operationalizing planned motivation schemes to boost acceptance of change including job rotation and job enrichment

HR Consultants \& Experts

HR Training Co.

\section{"HR must base their workforce plans (recruiting, selecting, $\quad 1$ ) Clear job analysis}

succession, etc.) on the change concept, where they should get 2 2) Always suggesting that employees' continuous out of the rigid fixed hierarchies and job descriptions, and try to development is a must

$\begin{array}{ll}\text { plan based on the flexibility concept" } & \text { 3) Conducting open discussion with employees about }\end{array}$

future competency changes and the methods they will be

"Human resources in the change process must recruit and select trained in, is a must as well talents and workers with competences that belong to the same culture of the organization that can lead to a smooth transition "HRM sets up training and development activities required in the change process" to functional change."

"Job rotation while in the change process helps to implement the change in a better way using the experienced workers"

1) Share clearly objectives of $T \& D$ with employees

2) Modify incentives system accompanying T\&D

1) Emphasizing the human behavior values in the strategy to lower barriers against planned change

"We conduct clear job analysis to offer the rightful competenciestraining"

" $H R$ and immediate supervisors of the trainees are invited to discuss openly with trainees the objectives of the to the client"

"Module training through workshops is an effective method" 
Table 4. Specific Roles of HRM in Change management.

\begin{tabular}{|c|c|c|}
\hline & HR Development: Performance Management & HR Development: Total Rewards \\
\hline \multirow{6}{*}{$\begin{array}{l}\text { HR Managers \& } \\
\text { Officers }\end{array}$} & 1) Performance management is an essential part of HR strategy. & 1) Clear policies for rewarding employees are set. \\
\hline & This view is observed during the last decade & 2) Change cannot succeed without full acceptance from \\
\hline & 2) Performance gaps mitigation strategies fit change & employees, and therefore to encourage that, incentives are \\
\hline & management requirements to guarantee a change in behavior & planned. \\
\hline & $\begin{array}{l}\text { and an improvement of competencies. This is especially } \\
\text { important in new universities }\end{array}$ & $\begin{array}{l}\text { "During our initiation phases requiring many changes, } \\
\text { employees were provided with different incentives }\end{array}$ \\
\hline & “Transparency is essential to attract employees engagement" & including tangible and intangible ones" \\
\hline \multirow[t]{4}{*}{ HR Media Co. } & $\begin{array}{l}\text { 1) Performance management fits the organization's HR strategy } \\
\text { "Revisiting our performance appraisal applications is necessary } \\
\text { to keep up with market requirements" }\end{array}$ & $\begin{array}{l}\text { "We are generous with incentives to keep our employees' } \\
\text { creativity high and to accept changes that are governed by } \\
\text { our clients or by our system" }\end{array}$ \\
\hline & & 1) Employees look for incentives whenever they are \\
\hline & 1) The strategic impact of performance management is assessed & informed that there are changes in their jobs. \\
\hline & $\begin{array}{l}\text { within a change management direction whereby transparency of } \\
\text { its application is a must }\end{array}$ & $\begin{array}{l}\text { f 2) Employees may be resistant if they are ignored and not } \\
\text { appreciated during a change process }\end{array}$ \\
\hline \multirow[t]{5}{*}{ HR Professors } & "Allowing employees to contribute in the appraisal process will & "It is extremely important to motivate change agents \\
\hline & $\begin{array}{l}\text { lead to certain measures that will classify employees in order to } \\
\text { manage their performance and guide them to enhance their }\end{array}$ & through financial benefits" \\
\hline & performance among change implementation" & $\begin{array}{l}\text { "An organization can give bonuses and allowances to } \\
\text { encourage people for adapting or initiating change." }\end{array}$ \\
\hline & $\begin{array}{l}\text { No doubt that many Lebanese organization have to revisit their } \\
\text { performance management approaches }\end{array}$ & \\
\hline & & 1) Planning for a clear and fair reward system motivates \\
\hline \multirow{4}{*}{$\begin{array}{l}\text { HR Consultants \& } \\
\text { Experts }\end{array}$} & "The most important aspect to appraise in the change process is & employees to accept the change \\
\hline & $\begin{array}{l}\text { the ability to handle and accept and contribute to change and } \\
\text { the productivity that the employee offers during this process" }\end{array}$ & $\begin{array}{l}\text { "An organization surely must set up a rewards system that } \\
\text { supports and motivates change" }\end{array}$ \\
\hline & $\begin{array}{l}\text { "An organization surely must set up a rewards system that } \\
\text { supports and motivates change" }\end{array}$ & \\
\hline & $\begin{array}{l}\text { Training personnel of Lebanese SMEs HR function related to } \\
\text { performance appraisal is a popular request }\end{array}$ & $\begin{array}{l}\text { 1) It is a fundamental step to couple a clear reward system } \\
\text { to the T\&D exercises. }\end{array}$ \\
\hline \multirow[t]{2}{*}{ HR Training Co. } & $\begin{array}{l}\text { "Keeping an eye on the quality of production during the phase } \\
\text { of performance appraisal taking into account the change process }\end{array}$ & $\begin{array}{l}\text { "Our experience is that employees embrace change to how } \\
\text { s they do things if they are rewarded and informed about the }\end{array}$ \\
\hline & helps institutions to mitigate gaps in competencies" & change beforehand" \\
\hline
\end{tabular}

Employee and Labor Relations (ELR) and Risk Management ( $R M$ )

Andy Swann, a workplace consultant at BDG, quoted in "People Management Insight [44]" asserted that "When people own change, they engage positively with it" (p. 10). Interviewee' inputs are summarized in Table 5.

\section{Leadership, HRM, and Change Management}

One fundamental condition for the success of change programs is having a complete fit between the organizations' leadership, their HR function, and clear and purposeful change management plans. According to Burnes and Jackson [16] report, " $70 \%$ of all change initiatives fail. One potentially significant reason for this is a lack of alignment between the value system of the change intervention and of those members of an organization undergoing the change" (p. 133). Furthermore, organizational value system is triggered by the leadership, a fact that adds huge responsibility towards change management initiatives which may 
lead to either success or failure of change programs. Other researchers stress the importance of having adequate leadership. "Through appropriate leadership style and leaders' participation" [46], and having "leaders who act as role drivers as well as role models" [47], leaders would be able to "influence and ultimately change the behaviors of employees, teams and the organization at large" [48] (p. 147). The aforementioned are determinants of success in organizational change programs. Success of initiatives for change therefore depends on the leaders' preparation adequacy of the self as well as their institutions for the change programs [49].

Next, Table 6: shows what the interviewees opined about the matter.

Table 5. Specific Roles of HRM in Change management.

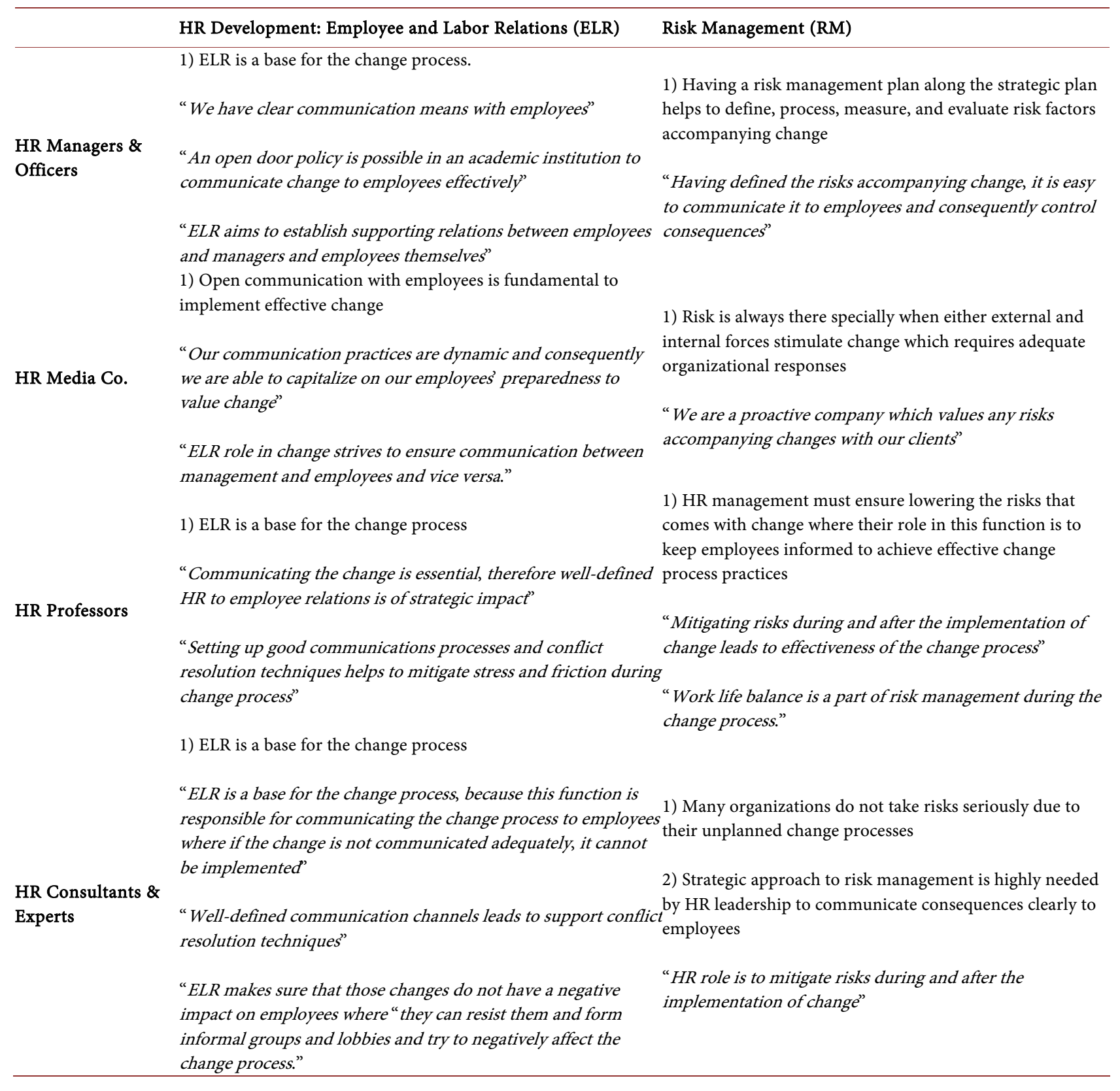




\title{
Continued
}

\begin{tabular}{|c|c|c|}
\hline \multirow{2}{*}{ HR Training Co. } & $\begin{array}{l}\text { 1) Organizations seeking effective change need clear and } \\
\text { transparent communication practices }\end{array}$ & $\begin{array}{l}\text { 1) The dynamic behavior of change requires a dynamic } \\
\text { behavior toward risk. The HR function is highly concerned } \\
\text { to help employees take informed decisions }\end{array}$ \\
\hline & $\begin{array}{l}\text { "We practice clear communication internally and externally to } \\
\text { mitigate any issues related to changes in our processes" }\end{array}$ & $\begin{array}{l}\text { "Organizations need to undertake risk management } \\
\text { training to all employees to mitigate negative consequences } \\
\text { of change" }\end{array}$ \\
\hline
\end{tabular}

Table 6. Leadership, HRM and change management.

As leadership have pivotal part in the process of change, academics and professionals agree on the fact that leadership is essential in the change process, where one academicians assert that:

\begin{abstract}
Interviewees 5-7 [summarizing their statements in one paragraph]
"Without leadership we cannot have change, because we need change to be lasting, a leader enlists a vision and people follow that leader and the change that he wants thus initiating and sustaining the change, and human resources can play the role of the leader because they know people well and they have the ability to convince those people that this change is an opportunity not a threat."
\end{abstract}

On the other hand, the consultants and experts contend:

Interviewees 8-10 [in a briefly summarized statement]:

"Knowing that the style of leadership differs because every situation needs a certain style of leadership but "leadership is a must"

Furthermore, the HR managers and officers of the Universities in addition to the Media Organization HR manager assert that:

Interviewees 1-4:

"Those styles differ from being autocratic to democratic to transactional but"today's leadership trend is the servant and transformational leadership styles."

The training organization $H R$, Interviewees 11 and 12 , assure:

"Organizational change is dynamic, thus it is directly linked to HRM whose personnel provide guidance and support the people managing the change process."

Finally, one professor adds Interviewee 6:

"HRM facilitates change management and the two concepts are firmly bonded with each other because whenever change takes place, HR is there to play a key role, and when talking about that bond HRM must integrate all the changes with the HR functions in order to implement change."

\section{Conclusion and Recommendations}

This study was carried out to assess the relation between Human Resource Management and the Change Process from the point of view of a selected number of Lebanese academicians and practitioners who actually practice contemporary HR functions. In-depth semi structured interviews revealed that the managers, experts, professionals and professors transmitted the actual view of Lebanese companies' practices related to HR management key roles in change management. However, the realities of the matter lead to what Deshler [50] has reported that "many leaders learn through trial and error how to lead effectively during change. Unfortunately, their learning curve can be at the expense of the organization" (Para 6). The reason, which has been observed in many Lebanese organizations matches what Deshler [50] found as well, "Having and practicing a change management mentality are two different things. Lots of leaders want change, but only a select few actually help make it happen" (Para 4).

This study was based on an open system approach which characterizes organizations as open organisms which are in dynamic exchange of resources with their external business environment forces. More specifically, the results stressed 
on the impact of the external and internal environments of the organization, fitting triggers for change management ([19] [40] [51]). The outcome is to renew, on a continuous basis, an organizational direction, structure, and capabilities to adapt, offer quick response and serve the ever changing needs of customers (external and internal). Further, this study aimed to identify the HR management role in the ongoing change process in organizations. The general role of HR management in the process of change was asserted by the interviewees and summarized by the fact that organizations continuously seek innovating change and keeping up with it to monitor and correct any observed gaps as asserted by Lockwood [10]. Also, emphasis was stressed on the role of coupling the change process to organizational strategy as recommended by Adeniji, Osibanjo, \& Abiodun [33]. Further, researchers like Akinbode and Al Shuhumi [49] posit that "Strategic change has to do with broad, long-term and organization-wide range issues. In implementing this change, the purpose and mission of the organization, as well as its corporate philosophy are considered. The change leaders also carry out the required SWOT (by considering the Strength, Weakness, Opportunities and Threats) analysis to determine how the change program will be initiated" (p. 612).

HR practitioners and professionals [both academicians and experts] are aware of the barriers which may cause serious problems to the success of the change process in the organization, where the change would not be positive and sustainable if HR did not act upon its roles correctly. In particular, interviewees warned against not involving employees fully in the process as advised by Korn Ferry [45], which strongly recommends organizational leaders to "employ critical communications strategies that weave new programs into the fabric of the organization, and define and reinforce each person's role in implementing smart rewards strategies for a bright and successful future" (Para 2).

\section{Recommendations}

Managers and HR professionals must be knowledgeable of the change process and must be ready along the five HR functions to framework and plan change, also they must have compatible leadership skills in order to ensure the smooth transition of state, thus, leading to reduction of resistance and increasing productivity. One golden rule here is the full engagement of employees. People Management Insight [44], quotes Andy Swann, a workplace consultant at BDG, in "The challenges and opportunities facing HR in 2017" report, saying "It's not a case of completely changing an organization's structure to allow constant, natural evolution, it's more a case of unleashing people through the flow of information up, down and around the organization. It's not so complicated and when this happens, change can be adopted much more easily". Swann (quoted in [44]) has "five golden rules for companies undergoing a change management program: 1) Put people first; 2) Consider the impact; 3) Give everyone ownership of the change; 4) Communicate constantly and openly; and 5) Think differently" (p. 11). 
This research has the tribute of being one of the first to address the topic, though limitations also exist manifested with the small sample leading to the fact that findings and results may not be generalized but may be taken seriously as indicators for future work. Future research is to run a quantitative study across the diverse economic sector institutions of Lebanon to assess best practices and explore to what extent these organizations are aware of the importance of the $\mathrm{HR}$ role in the change process.

The findings of this study could be validated in future studies and research where researchers from Lebanon and abroad are invited to explore and assess to what extent organizations are aware about the change management approaches with the HR function acting as a change agent.

\section{Implications}

This research is considered an eye opener and therefore with positive contribution to the scarce literature about the HR role in the change management in Lebanon. The outcomes are encouraging though exploratory in nature necessitating that researchers in Lebanon as well as the region run similar studies to create a clearer view about the awareness of the HR role and the understanding of change management process and its requirements. Furthermore, explore the readiness of the Lebanese and the regional job markets to deal with changes in all aspects and the needed competencies for consultants and strategists. HR functions in Lebanese organizations need to be aware that they must institute employee engagement programs, a fact that will mitigate resistance for the coming change plans of their organizations.

\section{Conflicts of Interest}

The authors declare no conflicts of interest regarding the publication of this paper.

\section{References}

[1] Schein, E.H. (2010) Organizational Culture and Leadership. 4th Edition, Wiley, San Francisco.

[2] Jones, G. (2010) Organizational Theory, Design and Change. 6th Edition, Pearson Education Limited, Upper Saddle River.

[3] Cummings, T.G. and Worley, C.G. (2009) Organization Development \& Change. 9th Edition, South-Western/Cengage Learning, Boston.

https://www.cengage.com/custom/static content/OLC/1111067902/data/cummings 21389032442138902.09 chapter09.pdf

[4] Hussain, S.T., Lei, S., Akram, T., Haider, M.J., Hussain, S.H. and Ali, M. (2018) Kurt Lewin's Process Model for Organizational Change: The Role of Leadership and Employee Involvement: A Critical Review. Journal of Innovation and Knowledge, 3, 123-127. https://doi.org/10.1016/j.jik.2016.07.002

[5] Oreg, S. (2006) Personality Context and Resistance to Organizational Change. European Journal of Work and Organizational Psychology, 15, 73-103.

https://doi.org/10.1080/13594320500451247 
[6] Furst, S.A. and Cable, D.M. (2008) Employee Resistance to Organizational Change: Managerial Influence Tactics and Leader Member Exchange. Journal of Applied Psychology, 93, 453-463. https://doi.org/10.1037/0021-9010.93.2.453

[7] Gartner (2018) Manage Change More Successfully. https://www.gartner.com/en/insights/change-management

[8] Pierce, J.L., Gardner, D.G. and Dunham, R.B. (2002) Management Organizational Change and Development. In: Management and Organizational Behavior. An Integrated Perspective, South-Western College Publishing, Chapter 18, Cincinnati, 627-657.

[9] Cook, S. and Macaulay, S. (2004) Change Management Excellence. Kogan Page, London.

[10] Lockwood, N. (2007) An HR Perspective: Change Management. https://www.shrm.org/hr-today/trends-and-forecasting/research-and-surveys/docu ments $/ 2007 \% 20$ change $\% 20$ management $\% 20$ survey\%20report.pdf

[11] Collarbone, P. (2012) Leading Change, Change Leadership. Center for Strategic Education, Occasional Paper 126. https://www.cse.edu.au/zfiles/CSE-Pat-Collarbone.pdf

[12] Mathieu, J.E., Gilson, L.L. and Rubby, T.M. (2006) Empowerment and Team Effectiveness: An Empirical Test of an Integrated Model. Journal of Applied Psychology, 91, 97-108. https://doi.org/10.1037/0021-9010.91.1.97

[13] Society for Human Resource Management SHRM (2019) Managing Organizational Change. https://www.shrm.org/resourcesandtools/tools-and-samples/toolkits/pages/managi ngorganizationalchange.aspx

[14] Lewin, K. (1951) Field Theory in Social Science: Selected Theoretical Papers (ed. Cartwright, D.). Harper \& Row, New York.

[15] Robbins, S.P. and Judge, T.A. (2013) Organizational Behavior. 15th Edition, Pearson Education Limited, Upper Saddle River.

[16] Burnes, B. and Jackson, P. (2011) Success and Failure in Organizational Change: An Exploration of the Role of Values. Journal of Change Management, 11, 133-162. https://doi.org/10.1080/14697017.2010.524655

[17] Kotter, J.P. (1995) Leading Change: Why Transformation Efforts Fail. Harvard Business Review, 73, 59-67.

[18] Anderson, D. and Anderson, L.S. (2001) Beyond Change Management: Advanced Strategies for Today's Transformational Leaders. Jossey-Bass/Pfeiffer, San Francisco.

[19] McMillan, E. (2004) Complexity, Organizations and Change. Routledge, London. https://doi.org/10.4324/9780203507124

[20] Oakland, J.S. and Tanner, S.J. (2007) A New Framework for Managing Change. The TQM Magazine, 19, 572-589. https://doi.org/10.1108/09544780710828421

[21] Ryerson University (2011) Change Management Leadership Guide. Human Resources.

https://www.ryerson.ca/content/dam/hr/manager-resources/docs/change-managem ent-leadership-guide.pdf

[22] Cameron, E. and Green, M. (2009) Making Sense of Change Management. 2nd Edition, Kogan Page, London.

[23] Collarbone, P. (2009) Creating Tomorrow: Planning, Developing and Sustaining Change in Education and Other Public Services. Bloomsbury, Sydney. 
[24] Todnem, R., Kuipers, B. and Procter, S. (2018) Understanding Teams in Order to Understand Organizational Change: The OTIC Model of Organizational Change. Journal of Change Management, 18, 1-9. https://doi.org/10.1080/14697017.2018.1433742

[25] Mar, A. (2013) 4 Types of Change Management (Levels). https://management.simplicable.com/management/new/4-types-of-change-manage ment

[26] Paycor (2016) Overcoming Employee Resistance to Change in the Workplace. https://www.paycor.com/resource-center/change-management-in-the-workplace-w hy-do-employees-resist-it

[27] Yılmaz, D. and Kılıçoğlu, G. (2013) Resistance to Change and Ways of Reducing Resistance in Educational Organizations. European Journal of Research on Education, 1, 14-21.

[28] Expert Program Management (EPM) (2019) Six Change Approaches. https:/expertprogrammanagement.com/2018/05/six-change-approaches

[29] Robbins, S.P. and Judge, T.A. (2016) Organizational Behavior. 17th Edition, Pearson Education Limited, Upper Saddle River.

[30] Smith, C. (2018) 3 Types of Resistance to Change ... and What to Do about Them [Blog]. https://change.walkme.com/resistance-to-change

[31] Griffin, W.R. (2006) Management. 8th Edition, Houghton Mifflin Company, Boston, 7.

[32] Benedict, A. (2007) 2007 Change Management: Survey Report. Society for Human Resource Management (SHRM), Alexandria.

[33] Adeniji, A.A., Osibanjo, O.A. and Abiodun, A.J. (2013) Organizational Change and Human Resource Management Interventions: An Investigation of the Nigerian Banking Industry. Serbian Journal of Management, 8, 139-154. https://doi.org/10.5937/sjm8-3712

[34] Macky, K. and Boxall, P. (2007) The Relationship between "High-Performance Work Practices" and Employee Attitudes: An Investigation of Additive and Interaction Effects. International Journal of Human Resource Management, 18, 537-567. https://doi.org/10.1080/09585190601178745

[35] Tummers, L.G., Kruyen, P., Vijverberg, D. and Voesenek, T. (2015) Connecting HRM and Change Management: The Importance of Proactivity and Vitality. Journal of Organizational Change Management, 28, 627-640. https://doi.org/10.1108/JOCM-11-2013-0220

[36] Mamin Ullah, M. (2012) The Emerging Roles of HR Professionals in Driving Organizational Change. Journal of Knowledge Management, Economics and Information Technology, 2, 121-132.

[37] Browning, S.M. (2015) Four Steps to Effective Change Management for HR. https://www.tlnt.com/four-steps-to-effective-change-management-for-hr

[38] Hejase, A.J. and Hejase, H.J. (2013) Research Methods: A Practical Approach for Business Students. 2nd Edition, Masadir Inc., Philadelphia.

[39] Ministry of Economy and Trade-MoET (2014) Lebanon SME Strategy: A Roadmap to 2020. Inventis. https://www.economy.gov.lb/public/uploads/files/6833 5879 4642.pdf

[40] Robbins, S.P. and Coulter, M. (2016) Management. 13th Edition, Pearson Education Limited, Harlow.

[41] Zafar, F., Iqbal, Y., Azad, M.T. and Afsar, R.J. (2014) Human Resource Role in 
Change Management during Cross Border Mergers. IOSR Journal of Business and Management, 16, 54-61. https://doi.org/10.9790/487X-16145461 https://pdfs.semanticscholar.org/8baa/ec0ffa18acb65cfe5ef94dc726d5091abf91.pdf

[42] Lunenburg, F.C. (2010) Managing Change: The Role of the Change Agent. International Journal of Management Business, and Administration, 13, 1-6.

[43] Walcroft, B. (2017) Put People First: The Role of HR in Managing Change in the Workplace.

https://www.corehr.com/blog/the-role-of-hr-in-managing-change-in-the-workplace

[44] People Management Insight (2017) The Challenges and Opportunities Facing HR in 2017.

https://pminsight.cipd.co.uk/the-challenges-and-opportunities-facing-hr-in-2017

[45] Ferry, K. (2019) Rewards Change Management. https://www.kornferry.com/solutions/rewards-and-benefits/employee-rewards/rew ards-change-management

[46] Oreg, S., Vakola, M. and Armenakis, A. (2011) Change Recipients' Reactions to Organizational Change. The Journal of Applied Behavioral Science, 47, 461-524. https://doi.org/10.1177/0021886310396550

[47] Skakon, J., Nielsen, K., Borg, V. and Guzman, J. (2010) Are Leaders' Well-Being, Behaviours and Style Associated with the Affective Well-Being of Their Employees? A Systematic Review of Three Decades of Research. Work \& Stress, 24, 107-139. https://doi.org/10.1080/02678373.2010.495262

[48] Baesu, C. and Bejinaru, R. (2013) Leadership Approaches Regarding the Organization Change. The USV Annals of Economics and Public Administration Journal, 2, 146-152.

[49] Akinbode, A.I. and Al Shuhumi, S.R.A. (2018) Change Management Process and Leadership Styles. PEOPLE: International Journal of Social Sciences, 4, 609-618. https://doi.org/10.20319/pijss.2018.42.609618

[50] Deshler, R. (2016) The Role of Leadership in Change Management. https://alignorg.com/the-role-of-leadership-in-change-management

[51] Moran, J.W. and Brightman, B.K. (2000) Leading Organizational Change. Journal of Workplace Learning, 12, 66-74. https://doi.org/10.1108/13665620010316226 